Farum

Sociológico

\section{Forum Sociológico}

Série II

$34 \mid 2019$

Habitação nas áreas urbanas de Lisboa e Porto: Da comunidade aos decisores políticos

\title{
Necessidade, oportunidade e ilegalidade em habitação - alojamento local e tendências contemporâneas
}

Need, opportunity and illegality in housing - short-term rentals and contemporary trends

Inês Calor e Mateus Magarotto

\section{(2) OpenEdition}

Journals

Edição electrónica

URL: https://journals.openedition.org/sociologico/4753

DOI: $10.4000 /$ sociologico. 4753

ISSN: 2182-7427

Editora

CICS.NOVA - Centro Interdisciplinar de Ciências Sociais da Universidade Nova de Lisboa

Edição impressa

Paginação: 43-50

ISSN: 0872-8380

Refêrencia eletrónica

Inês Calor e Mateus Magarotto, «Necessidade, oportunidade e ilegalidade em habitação - alojamento local e tendências contemporâneas», Forum Sociológico [Online], 34 | 2019, posto online no dia 19 agosto 2019, consultado o 30 março 2022. URL: http://journals.openedition.org/sociologico/4753 ; DOI: https://doi.org/10.4000/sociologico.4753 


\title{
NECESSIDADE, OPORTUNIDADE E ILEGALIDADE EM HABITAÇÃO - ALOJAMENTO LOCAL E TENDÊNCIAS CONTEMPORÂNEAS \\ NEED, OPPORTUNITY AND ILLEGALITY IN HOUSING - SHORT-TERM RENTALS AND CONTEMPORARY TRENDS
}

\section{Inês Calor}

CEGOT - Departamento de Geografia da Universidade do Porto

\section{Mateus Magarotto}

- LEGECE - Departamento de Oceanografia da Universidade Federal de Pernambuco e CEGOT - Departamento de Geografia da Universidade do Porto

\begin{abstract}
Resumo
O arrendamento de curta duração de habitação está num processo rápido de mudança para um novo paradigma setorial onde as plataformas online (como a Airbnb) têm um papel preponderante. A imposição de restrições à atividade faz parte da agenda social e política da maioria dos países europeus. Contudo, conforme demonstram as primeiras tentativas, regulamentar não é suficiente, visto os promotores ignorarem muitas vezes as regras impostas. A monitorização e a fiscalização acarretam grandes dificuldades para a administração pública.

Este artigo foca-se nas regras desenhadas para o alojamento local e no alcance das medidas implementadas em Portugal. Traça um esboço da ilegalidade urbanística nesta área na era da economia partilhada, abordando as estratégias de regulação e os resultados alcançados. A conclusão aponta para o facto de a verificação do cumprimento das obrigações legais de registo ou fiscais ser uma questão de justiça e responsabilidade social.
\end{abstract}

Palavras-chave: Airbnb, habitação, turismo

\begin{abstract}
Short-term housing rentals are in a rapid shift to a new sectorial paradigm where online platforms (such as Airbnb) play a significant role. The restrictions on the rentals of entire apartments are on the social and political agenda of most European countries. However, as the first attempts demonstrate, regulation is not enough, as owners often ignore it. The monitoring and enforcement of such rules entails great difficulties for public administrations.

This article focuses on the rules designed and measures for short-term rentals implemented in Portugal. It outlines the urbanistic illegalities in this field in the age of shared economy, addressing the regulatory strategies adopted and the results achieved. The conclusions point out that the compliance with registration and taxation rules is a matter of justice and social responsibility.
\end{abstract}

Keywords: Airbnb, housing, tourism

\section{Mudanças na cidade e na habitação}

O direito à habitação é consagrado pela Carta Universal dos Direitos Humanos e pela Constituição. Contudo, no contexto neoliberal, a habitação não é apenas um lugar para "habitar", mas sim um bem de consumo dinâmico e em constante mutação. As plataformas online têm um crescente impacto na sociedade e na vida urbana, permitindo a fácil ligação entre pessoas e a oferta do mais variado tipo de serviços. A chamada "economia de partilha" (de bens desaproveitados ou subaproveitados), das quais se 
tornaram ícones as plataformas Uber e Airbnb, veio alterar definitivamente as formas tradicionais de transporte, alojamento, turismo e, por consequência, a forma de habitar as cidades. Este crescimento da economia de partilha ou "economia da confiança" é defendido por muitos economistas como um novo paradigma económico e prevê-se que poderá vir ainda a alterar de forma substancial o setor de serviços (Dudás, Vida, Kovalcsik, \& Boros, 2017). Inserido nesta temática, o arrendamento de curta duração cresceu exponencialmente nos últimos anos, alavancado pela implementação de aplicações web que colocam a oferta de alojamentos de todo o mundo à distância de um clique. A última contagem da Airbnb indica a sua utilização por quase 300 milhões de hóspedes distribuídos por 191 países $^{1}$. O surgimento de outras plataformas online similares, como a HomeAway e a VRBO, revelam uma predisposição geral para a aceitação deste tipo de serviços e interação.

A facilidade de acesso dos utilizadores e a oferta de uma grande diversidade de alojamentos é hoje um fator importante na tomada de decisão de uma pessoa viajar ou de se hospedar em qualquer parte do mundo. Nos últimos anos, a implementação de plataformas de economia de partilha é levada a cabo por um processo de reestruturação da oferta de equipamentos, estruturas de lazer e habitação. As novas tecnologias, associadas a produtos turísticos, formam a base do conceito de unidades hoteleiras, como forma de valorização do seu modelo de negócio, mas também da criação competitiva de formas alternativas de alojamento (Munkøe, 2017). A valorização do modelo de negócio e a criação competitiva de alojamento estão cada vez mais segmentadas e influenciadas pelas alterações ao nível do consumidor, sobretudo na última década (Turismo de Portugal, 2007).

Volvidos poucos anos desde o seu surgimento, estas novas formas de hospedagem causaram um profundo impacto económico, social e urbano. Por um lado, criaram a oportunidade de proprietários singulares obterem rendimentos significativos (complementares à economia familiar ou a criação de postos de trabalho), fomentaram a tão necessária reabilitação urbana nos centros das cidades (Lopes, 2018) e proporcionaram o aumento da capacidade turística, contribuindo para o crescimento económico favorável.

Por outro lado, as externalidades negativas são fortemente contestadas: a concorrência à indústria hoteleira, a perturbação da tranquilidade e a segurança dos edifícios de habitação coletiva e, em especial, o aumento significativo do preço da habitação. Nas principais cidades portuguesas, a ausência de políticas públicas para habitação acessível, a alteração à Lei do Arrendamento e os programas de reabilitação urbana (Mendes, 2014) facilitaram o processo de gentrificação, promovendo a deslocação da população mais desfavorecida para fora do centro das cidades. Além destas inquietações, o princípio de "partilha" da Airbnb tem merecido crescentes ataques, perante a evidência de uma elevada percentagem da oferta de alojamentos ser referente a apartamentos inteiros, onde o anfitrião não está presente e a profissionalização dos serviços se aproxima dos serviços hoteleiros.

Por definição legal², a designação de alojamento local engloba os estabelecimentos "que prestem serviços de alojamento temporário a turistas, mediante remuneração" e que não "reúnam os requisitos para serem considerados empreendimentos turísticos". Apesar da distinção, são atividades naturalmente concorrentes. No entanto, estudos recentes mostram que o impacto da presença do alojamento local no sector hoteleiro tem sido moderado, sendo mantidos os níveis de lucro da maioria dos hotéis mas trazendo dificuldades aos estabelecimentos voltados para o segmento mais económico (AHRESP, 2016). Os reflexos do alojamento local no aumento do preço da habitação tendem a ser também desvalorizados na literatura académica, sendo as causas do aumento dos preços apontada à conjugação de vários fatores, dos quais se destaca o incentivo ao investimento estrangeiro (Lopes, 2018). No entanto, o aumento do preço da habitação é encarado como o problema atual mais premente do ponto de vista urbanístico, social e habitacional.

Em Portugal é especialmente preocupante a escalada do preço de venda de habitação, estimado em 20\% entre 2015 e 2017 (INE, 2017). Este período de florescimento do alojamento local é exacerbado pela relativa facilidade na obtenção de crédito. O valor médio dos novos empréstimos aproxima-se dos 100 mil euros, montante mais elevado desde janeiro de 2009, período antes do início da crise (INE, 2017). Por outro lado, o arrendamento de longa duração (historicamente com pouca expressão em Portugal) sofre uma escassez crónica de oferta e subida desproporcionada nos preços. Depois de décadas de congelamento de rendas, os desalojamentos sucedem-se e os apartamentos disponíveis no centro das principais cidades são destinados a outros fins.

A valorização exacerbada dos imóveis no centro das grandes cidades não é um problema novo, sendo o progressivo esvaziamento a favor das atividades comerciais e de serviços um problema reconhecido há décadas (Mendes, 2014). Contudo, o fenómeno do alojamento local tem a capacidade de exercer influência numa área geograficamente muito mais alargada e, sobretudo, a velocidade da mudança em curso não tem precedentes. Por isso, a (sobre)valorização da função habitacional é, nestes níveis, um problema novo e de grande impacto para as cidades.

A administração nacional e a administração local têm hoje um dilema em mãos, na forma de regular 
esta nova atividade. O processo de "turistificação" do centro das cidades parece ser irreversível. A intervenção do estado e a imposição de restrições ao arrendamento de apartamentos inteiros faz parte da agenda social e política atual na maioria dos países europeus (Dudás et al., 2017). Contudo, conforme demonstram as primeiras tentativas de desenhar medidas regulamentares, não é suficiente para que estas atinjam efeitos práticos. Perante a magnitude dos interesses e lucros em perspetiva, a tendência dos promotores é ignorar as restrições impostas. A monitorização e a fiscalização das regras desenhadas até ao momento acarretam grandes dificuldades de ordem prática para a maioria das entidades da administração.

Nesse sentido, este artigo pretende focar-se nas questões atinentes aos problemas da monitorização e fiscalização das regras desenhadas para o alojamento local, abordando o alcance das medidas implementadas até ao momento em Portugal. Estruturado em dois capítulos centrais, em primeira instância, este ensaio traça um esboço daquilo que é a informalidade na era da economia partilhada e, em segunda instância, aborda as estratégias de regulação adotadas e os resultados alcançados.

\section{A informalidade na era da economia partilhada}

A necessidade de habitação primária é legitimamente entendida como o principal argumento para o surgimento de bairros de lata, loteamentos ilegais e habitações "marginais". Esta perspetiva é especialmente acolhida em países em desenvolvimento e em outros países mais desenvolvidos, com maior enfoque numa camada social desfavorecida. Contudo, a ilegalidade urbanística não se consubstancia apenas neste contexto de necessidade. Ainda que com diferentes características, mesmo nos países mais desenvolvidos, os exemplos de ilegalidade urbanística são variados (Calor, 2017; Calor \& Alterman, 2017). Exemplos mediáticos de habitações ilegais (ou semilegais) podem ser encontrados em Inglaterra ou no Canadá. Em Portugal, um estudo realizado com base nos dados do INE aponta para a existência de mais de 282000 edificações ilegais construídas entre 1991 e 2011 (Calor, 2017). À semelhança de Portugal, noutros países mediterrâneos como a Grécia e Espanha os proprietários são audazes e a administração incapaz de lidar com o elevado número de infrações urbanísticas.

Perante este panorama, poderemos esperar que os promotores do alojamento local cumpram com as regras urbanísticas estabelecidas no momento e para o futuro? Importa realçar que os promotores do alojamento local não partem de uma "necessidade" de habitação própria, situando-se antes entre uma classe média com capital e habitação própria.
A delimitação dos conceitos de "habitação primária", "habitação secundária" e "alojamento turístico" são cada vez mais difíceis de traçar. Perante a possibilidade de rentabilização pecuniária, as mudanças no tecido habitacional são rápidas, profundas e com uma certa tendência para ignorar as regras estabelecidas. Estará o sistema de planeamento urbanístico preparado para a mudança de paradigma?

Devido às externalidades negativas, a sociedade e a opinião pública apelam por medidas que regulem a atividade de alojamento local. Restrições têm vindo a surgir em vários países e cidades com elevada presença e impacto do alojamento de curta duração. As estratégias são variadas. Em Londres é aplicado o limite de 90 dias ao arrendamento por particulares, salvo quando o proprietário obtenha uma licença urbanística para propriedade de arrendamento para férias. Em São Francisco (EUA), o limite é de 30 dias (Ferreri \& Sanyal, 2018; Gregory \& Halff, 2017; Martin, 2016). Já em Berlim, casas inteiras devem ser registadas e taxadas como casas de férias, tendo menos restrições o arrendamento de quartos na presença do anfitrião. Em Barcelona, o número de apartamentos foi restringido por áreas, através de zonamento específico (Segú, 2018). Numa atitude mais extremada, Nova Iorque atualizou recentemente as suas leis para banir a publicitação de alugueres de curta duração (Dudás et al., 2017; Gurran, 2017).

Contudo, a simples criação de regras não é garantia suficiente da implementação efetiva das restrições, e a administração debate-se com grandes dificuldades em fazer cumprir as regras. A atividade do alojamento local nem sempre é feita com a boa-fé dos proprietários e das suas responsabilidades perante as normas e regras implementadas, geralmente destinadas a diminuir as disparidades entre o arrendamento tradicional e o novo paradigma oferecido por plataformas online. A alta rentabilidade do setor fomenta soluções imaginativas. A pluralidade de anfitriões e a possibilidade de lucro faz aumentar a tendência para contornar as regras estabelecidas e alguns exemplos nitidamente "informais" podem ser encontrados nas plataformas online. Por preços vantajosos e abaixo dos valores de mercado é disponibilizada, por exemplo, uma garagem-bar com casa de banho no "arbusto mais próximo" em Praga, na República Checa, em $2015^{3}$ (Figura 1) ou uma caravana estacionada no centro de Nova Iorque com utilização das instalações sanitárias no ginásio próximo, em $2018^{4}$ (Figura 2). No entanto, na maioria dos casos, não é possível a "olho nu" identificar claramente a qualidade (e legalidade) dos alojamentos disponibilizados.

As estratégias das cidades para monitorizar e garantir o cumprimento das suas regras têm sido diversas. Em Londres um acordo com a plataforma 
Figura $1 \triangleright$ Anúncio de garagem/bar para arrendamento turístico, Praga, República Checa

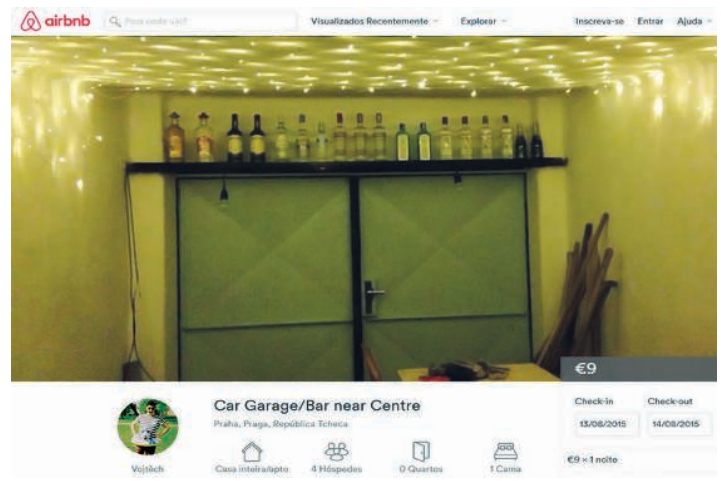

Fonte: Plataforma Airbnb (2015)

Airbnb garante o bloqueio automático para além dos 90 dias, mas surge a dúvida sobre se os proprietários irão cumprir ou simplesmente utilizar outras plataformas. Em 2016, a cidade de Barcelona multou a plataforma em 600 mil euros por continuar a publicitar quartos não licenciados, mas a prática continua. O número de inspetores dedicados a encontrar alojamentos ilegais em Barcelona tem vindo a ser amplamente reforçado, assim como o valor das multas (Segú, 2018). Em Nova Iorque, apesar da lei em vigor, continuam a ser publicitados milhares de anúncios de apartamentos inteiros (Dudás et al., 2017).

Devido à elevada pressão na obtenção de dados, surgem, por um lado, empresas dedicadas à extração de dados das plataformas, como a não-comercial Inside Airbnb ${ }^{5}$ e a comercial Airdna ${ }^{6}$. Esta última disponibiliza informação estatística e georreferenciada sobre as propriedades publicitadas na Airbnb nas principais cidades, utilizando sofisticados métodos de inteligência artificial para distinguir as datas de ocupação daquelas bloqueadas pelos anfitriões. Surgem ainda notícias de startups dedicadas a reunir informação sobre as atividades não regulamentares, para venda de informação a vizinhos ou às instituições da administração (Gurran \& Phibbs, 2017). Estas novas startups criam uma ferramenta importante na regulação não formal nesta era de economia de partilha. Atenta também às repercussões na vizinhança, a Airbnb criou em 2016 uma ferramenta online ${ }^{7}$ onde os vizinhos podem reclamar sobre o comportamento dos visitantes, prometendo que as queixas irão ser encaminhadas aos anfitriões.

Dada a juventude das medidas, ainda será cedo para avaliar o grau de eficácia das restrições e, mais importante, se as estratégias adotadas conseguirão minimizar a prevenção das principais externalidades negativas sentidas, nomeadamente a escalada do preço da habitação.
Figura $2 \triangleright$ Anúncio de carrinha vintage para arrendamento turístico, NI, EUA

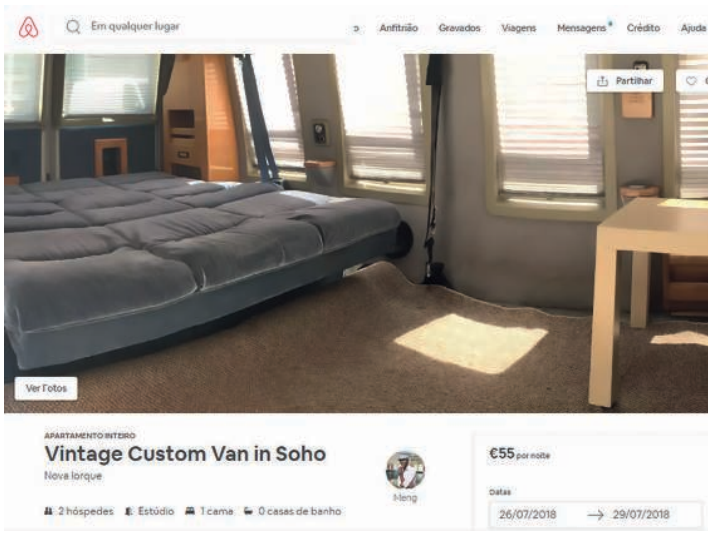

Fonte: Plataforma Airbnb (2018)

\section{Estratégias e regulação em Portugal}

Em Portugal, as propostas dos grupos parlamentares sucedem-se e a discussão do tema está também na ordem do dia. Contudo, quais são as perspetivas de a administração portuguesa conseguir efetivamente implementar normas restritivas ao alojamento local? Estará a administração portuguesa preparada para monitorizar, fiscalizar e lidar com os desvios às regras? Conseguirá obter sucesso onde outras cidades falharam até ao momento?

Com vista a um prognóstico, importa, por um lado, perceber o que foi feito até ao momento e, por outro, dar algumas notas sobre o comportamento da administração portuguesa na matéria mais genérica de ilegalidade urbanística.

Em Portugal, o alojamento local foi uma atividade sem enquadramento legal específico até 2008. A figura do alojamento local foi criada nesse ano ${ }^{8}$ para regular a prestação de serviços de alojamento temporário em estabelecimentos sem os requisitos legalmente exigidos para se qualificarem como empreendimentos turísticos. Em $2014^{9}$ a atividade passou a ser regulada por um documento legal específico e veio introduzir a obrigação de registo. O processo de registo pressupõe a apresentação de declaração de início de atividade no serviço de Finanças, com o respetivo Código de Atividade Económica (CAE) e a indicação do título de utilização da habitação (emitido pela Câmara Municipal no âmbito do licenciamento de obras particulares). Estas medidas visam, por um lado, mecanismos para garantir uma menor evasão fiscal e, por outro, assegurar as condições de habitabilidade dos alojamentos disponibilizados a turistas.

Em $2015^{10}$ o regime do alojamento local foi reforçado no sentido de tornar obrigatória a menção ao número de registo no anúncio e de estipular a correspondente contraordenação. A nível municipal, a 
preocupação é também de índole económica. Desde janeiro de 2016, o município de Lisboa aplica uma taxa turística, tendo sido seguido pelo município do Porto em março de 2018. À semelhança de outras cidades europeias, um acordo entre a Airbnb e os municípios de Lisboa e Porto garante a cobrança direta da taxa turística aplicável, ficando os proprietários responsáveis pela liquidação nos restantes casos. Assim, podemos dizer que as medidas aplicadas até ao momento têm subjacentes preocupações pecuniárias, não prefigurando qualquer restrição de índole urbanística, já que as taxas e impostos são aplicados de igual forma sem distinção de localização, densidade ou tipo de alojamento.

No sentido de combater a ausência de habitação a preços acessíveis a estudantes deslocados, o governo criou medidas positivas de incentivo ao aumento da oferta de habitação através do Plano Nacional de Alojamento para o Ensino Superior PNAES (República Portuguesa, 2018). O PNAES assenta prioritariamente na reabilitação de edificado existente, valorizando o património local e a coesão social. A questão do alojamento de estudantes exige uma estratégia integrada e a longo prazo (República Portuguesa, 2018). Esta é uma iniciativa que representa uma solução paliativa no caso específico dos estudantes, porém, será insuficiente para resolver a proliferação e o impacto do alojamento local nas principais cidades.

Com uma reduzida tradição de monitorização e fiscalização, o panorama português de efetiva implementação da (mínima) regulação da atividade não dá sinais positivos. Uma simples pesquisa na Airbnb revela a existência de vários anúncios sem referência ao registo ou, um pouco mais preocupante, em locais onde este não pode ser obtido, como por exemplo em áreas do domínio público (Calor \& Magarotto, 2018). Consubstanciando esta tese, um estudo da Nova School of Business and Economics e da Faculdade de Direito da Universidade Nova de Lisboa (AHRESP, 2016) denota que o número de alojamentos registados no Registo Nacional de Alojamento Local em setembro de 2016 é muito inferior aos anúncios publicitados na Airbnb em vários municípios portugueses. Na capital, a diferença é de quase 3500 propriedades, correspondendo a 37,4\% das propriedades publicitadas na Airbnb. As freguesias de Santa Maria Maior e da Misericórdia (em Lisboa) e o Centro na Cidade do Porto apresentam a maior disparidade nos números - alcançando mais de 50\% nas freguesias centrais no Porto. Curiosamente, uma notícia recente vem dar nota da superação em $50 \%$ das expectativas do município do Porto em relação à cobrança da taxa turística (Lusa, 2018). Sendo a taxa cobrada diretamente pela plataforma Airbnb, estará esta diferença relacionada com a diferença do número de alojamentos registados e aqueles efetivamente disponibilizados para arrendamento?
Estes resultados indiciam que uma elevada percentagem das propriedades operava sem registo em 2016 e provavelmente ainda se encontram nessa situação. Será interessante aferir em anos subsequentes se os números espelham o aumento ou diminuição desta disparidade entre alojamentos publicitados e registados. Nesta matéria não podemos deixar de refletir sobre a (sempre atual) pertinência da equação de Bowles que estima "20 por centro da população regulada irão automaticamente cumprir com qualquer regulamentação, cinco por cento tentarão não cumpri-la, e os restantes 75 por cento irão cumprir desde que pensem que os cinco por cento vão ser apanhados e punidos" (Bowles, 1971 in Zaelke et al., 2005, p. 24).

\section{Governança municipal e estratégia urbanística}

O intenso debate político sobre as restrições ao alojamento local culminou com a recente aprovação de uma segunda alteração ao regime do alojamento local ${ }^{11}$ com entrada em vigor no próximo dia 21 de outubro. As alterações introduzidas visam (entre as relacionadas com a salvaguarda das relações de vizinhança e condomínios) conferir aos municípios poderes para estabelecer zonamento, restrições ao número de alojamentos locais e cancelamento de registos. Esta lei habilita assim os municípios a traçarem a (tão necessária) estratégia de índole urbanística, enquanto ferramenta essencial para repor o equilíbrio com a função habitacional de longa duração e a preços acessíveis nas principais cidades do país.

Aguarda-se com expectativa saber como esta estratégia será delineada, mas, mais do que isso, se os municípios portugueses serão capazes de garantir a sua execução. Como demonstram os dados quantitativos acima mencionados, regulamentar não basta. A monitorização em continuum da atividade é uma peça essencial, sobretudo atendendo ao dinamismo do setor.

A nível da capacidade de monitorização e fiscalização dos municípios, as reticências são elevadas. Isto porque em matéria de fiscalização urbanística os municípios tendem a ser brandos e condescendentes. A afirmação de que "a fiscalização é o elo mais fraco do sistema de planeamento urbanístico" (Dobry, 1975 in McKay \& Ellis, 2005) mantém-se atual e pertinente. Em Portugal, por considerações políticas e económicas, as medidas de tutela da legalidade urbanística raramente são levadas até ao fim (Leite, 2010; Lopes, 2004). Um estudo baseado em entrevistas a vários municípios da região do Oeste e Vale do Tejo constatou que a postura municipal em relação às infrações urbanísticas em geral é deveras facilitadora e as suas ações minimizadas, para evitar "incómodos" aos 
particulares e à autarquia (Calor, 2017). A reduzida fiscalização é associada à facilitação da legalização de operações urbanísticas já consolidadas, para o que concorrem os argumentos de resolver o "problema" ao cidadão-eleitor e, por outro lado, de arrecadar as taxas urbanísticas associadas.

Por conta da pressão imobiliária é previsível que nas principais cidades portuguesas aumente a divisão de apartamentos com vista ao aumento do número de fogos. Este fenómeno é constatado em muitas cidades onde o preço da habitação é elevado. A subdivisão de casas ou frações em Inglaterra e a criação de novas unidades habitacionais em caves de habitações de Calgary são exemplos documentados na literatura (Cauvain \& Bouzarovski, 2016; Tanasescu, Wing-tak, \& Smart, 2010). Este tipo de transformação urbana é especialmente desafiador, por ter pouca expressão física externa e ser mais difícil de fiscalizar (do que, por exemplo, uma nova construção ou uma ampliação).

Como tal, a mudança de paradigma na fiscalização municipal é necessária para fazer face a estas mudanças e ao impulso do alojamento local. Uma regulamentação bem desenhada (com regras que sejam fiscalizáveis) e a especialização das equipas de fiscalização parecem uma inevitabilidade, bem como a agilização da estrutura municipal para uma resposta atempada. Estarão os municípios portugueses preparados para o desafio?

\section{Conclusão}

O rápido crescimento do alojamento local causou nas cidades portuguesas uma mudança de paradigma a nível urbanístico. O aumento do preço da habitação, a conflitualidade entre condóminos, a "turistificação" e o agravamento da terciarização dos centros das cidades são alguns dos problemas apontados. O crescimento do setor tem sido acompanhado pelas tentativas para regular a atividade. As medidas adotadas até ao momento têm enfoque nas questões pecuniárias e na receita para a administração, mas as alterações introduzidas recentemente abriram (por fim) a possibilidade de os municípios traçarem uma estratégia urbanística. Neste âmbito, do ponto de vista conceptual, o alojamento local é um interessante exemplo de como os conceitos de legalidade e ilegalidade são moldados pelas entidades reguladoras e mutáveis no decurso do tempo. Será importante fazer notar que o alojamento temporário para turistas não é uma atividade nova no nosso país, tendo precedentes sobejamente conhecidos no Algarve e nas zonas balneares. No entanto, até ao fenómeno de globalização proporcionado pelas plataformas online, esta foi uma atividade livre de restrições e merecedora de pouca atenção social.

Mas o desafio atual prende-se mais com a implementação do que com a regulação. O estudo da Nova School of Business and Economics de 2016 (AHRESP, 2016) demonstra que o alcance da regulamentação aplicável teve efeitos limitados. A diferença de $50 \%$ entre os alojamentos registados e aqueles publicitados na plataforma Airbnb no centro do Porto demonstra que não é suficiente produzir regulamentação, e a monitorização é um elemento-chave do processo.

Para as entidades públicas, a monitorização e fiscalização significa um esforço económico e de recursos humanos acrescidos. No caso dos municípios de Lisboa e Porto, e tendo em conta o acordo com a Airbnb constata-se que todos os alojamentos revertem para a taxa turística, mesmo quando não possuem registo. Ou seja, para alcançar maior receita, o interesse do município é ter o maior número possível de alojamentos, independentemente da sua condição de "legalidade". Com este paradigma repete-se um "velho" constrangimento dos particulares perante a administração quanto às construções ilegais: o facto de um segmento da administração (Serviço de Finanças) exigir a contribuição autárquica do imóvel e outro segmento (autarquias) alegar o desconhecimento da sua condição de ilegalidade. Esta aparente contradição repete-se no caso da taxa turística.

Nesta perspetiva, a verificação do cumprimento das obrigações legais de registo ou fiscais não deve ser encarada apenas como uma questão formal nem apenas como responsabilidade da administração, sendo antes uma questão de ordem, justiça e responsabilidade social. Por outro lado, para os consumidores existe também uma responsabilidade "social" que passa por proceder à verificação da legalidade do alojamento a arrendar, enquanto atitude consciente e de respeito pelos habitantes do local de destino.

\section{Notas}

1 https://press.airbnb.com/pt/fact-facts/ (acedido em 06/10/2018).

2 Artigo $2 .{ }^{\circ}$ do Decreto-Lei n. ${ }^{\circ}$ 128/2014, de 29 de agosto.

3 https://www.airbnb.pt/rooms/10457093 (acedido em 26/6/2015).

4 https://www.airbnb.pt/rooms/25374851 (acedido em 6/10/2018)

${ }^{5}$ http://insideairbnb.com/ (acedido a 01/10/2018).

${ }^{6}$ https://www.airdna.co/ (acedido a 01/10/2018).

https://www.airbnb.com.au/neighbors (acedido a 01/10/2018).

8 Decreto-Lei n. ${ }^{0}$ 39/2008, de 7 de março.

9 O Decreto-Lei n. ${ }^{\circ}$ 128/2014, de 29 de agosto, aprovou o regime jurídico da exploração dos estabelecimentos de alojamento local.

10 O Decreto-Lei 63/2015, de 23 de abril de agosto, altera o regime de autorização de exploração dos estabelecimentos 
de alojamento local, procedendo à primeira alteração ao Decreto-Lei n. ${ }^{\circ}$ 128/2014, de 29 de agosto.

11 Lei n. ${ }^{0} 62 / 2018$, de 22 de agosto, que altera o regime de autorização de exploração dos estabelecimentos de alojamento local, procedendo à segunda alteração ao Decreto-Lei n.o 128/2014, de 29 de agosto.

\section{Referências bibliográficas}

AHRESP. (2016). O Alojamento Local em Portugal qual o fenómeno ? (1. a ed.; AHP, Ed.). Lisboa, Portugal: AHP.

Bowles, C. (1971). Promises to Keep: My Years in Public Service, 1941-1969. HarperCollins.

Calor, I. (2017). A ilegalidade urbanística e o sistema de planeamento territorial. Perspetiva comparada sobre políticas e práticas de controlo urbanístico de obras particulares (tese de doutoramento). Lisboa: Faculdade de Ciências Sociais e Humanas. Universidade Nova de Lisboa.

Calor, I., \& Alterman, R. (2017). When enforcement fails. Comparative analysis of the legal and planning responses to non-compliant development in two advanced-economy countries. International. Journal of Law in the Built Environment, 9(3), 207-239. doi: 10.1108/IJLBE-06-2017-0021

Calor, I., \& Magarotto, M. G. (2018). Construções ilegais nas ilhas da Ria Formosa (Algarve, Portugal). In A. Miranda, M. Lopes, L. Tarelho, F. Martins, P. Roebeling, M. Coelho \& J. Labrincha (Eds.), CIALP - Conferência Internacional de Ambiente em Língua Portuguesa (pp. 582-592). Aveiro: Departamento de Ambiente e Ordenamento, Universidade de Aveiro.

Cauvain, J., \& Bouzarovski, S. (2016). Energy vulnerability in multiple occupancy housing: a problem that policy forgot. People, Place and Policy, 10(1), 88-106. doi: 10.3351/ppp.0010.0001.0007

Decreto-Lei n.o 128/2014 de 29 de Agosto. Diário da República n.o 166/2014 - Série I. Lisboa: Ministério da Economia

Decreto-Lei n. 0 39/2008 de 7 de Março. Diário da República n.o 48/2008 - Série I. Lisboa: Ministério da Economia e da Inovação

Decreto-Lei n.o 128/2014 de 29 de Agosto. Diário da República n.o 166/2014 - Série I. Lisboa: Ministério da Economia

Decreto-Lei 63/2015 de 23 de Abril. Diário da República n.o 79/2015 - Série I. Lisboa: Ministério da Economia

Dobry. (1975). Investigation into Planning Enforcement, The Dobry Report. London.

Dudás, G., Vida, G., Kovalcsik, T., \& Boros, L. (2017). A socio-economic analysis of Airbnb in New York City. Regional Statistics, 7(1), 135-151. doi:10.15196/ RS07108

Ferreri, M., \& Sanyal, R. (2018). Platform economies and urban planning: Airbnb and regulated deregulation in London. Urban Studies. doi: $10.1177 / 0042098017751982$
Gregory, A., \& Halff, G. (2017). Understanding public relations in the "sharing economy". Public Relations Review, 43(1), 4-13. doi: $10.1016 / \mathrm{j}$. pubrev.2016.10.008

Gurran, N. (2017). Global Home-Sharing, Local Communities and the Airbnb Debate: A Planning Research Agenda. Planning Theory and Practice, 9357, 1-7. doi:10.1080/14649357.2017.1383731

Gurran, N., \& Phibbs, P. (2017). When Tourists Move In: How Should Urban Planners Respond to Airbnb? Journal of the American Planning Association, 83(1), 80-92. doi:10.1080/01944363.2016.1249011

INE. (2017). Estatísticas da Construção e Habitação 2017 (1st ed.; I. INE, Ed.). Lisboa, Portugal: INE.

Lei n. ${ }^{\circ}$ 62/2018 de 22 de Agosto. Diário da República n. ${ }^{\circ}$ 161/2018 - Série I. Lisboa: Assembleia da República

Leite, A. (2010). Demolição vs Legalização. Não demolir, sem transigir -- que solução? In F. P. Oliveira (Ed.), O urbanismo, o ordenamento do território e os tribunais (pp. 461-476). Almedina.

Lopes, D. (2004). Medidas de tutela da legalidade urbanística. Revista CEDOUA, 14, 49-90.

Lopes, R. (2018). O impacte urbanístico e socioeconómico do Alojamento Local na cidade de Lisboa (WP 2018/05) Lisboa: Dinâmia-CET.

Lusa. (2018, Agosto 23). Taxa turística cobrada no Porto $50 \%$ acima das expetativas. Observador. Retirado de https://observador.pt/2018/08/23/ taxa-turistica-cobrada-no-porto-50-acima-dasexpetativas/

Martin, C. J. (2016). The sharing economy: A pathway to sustainability or a nightmarish form of neoliberal capitalism?. Ecological Economics, 121, 149-159. doi: 10.1016/j.ecolecon.2015.11.027

McKay, S., \& Ellis, G. (2005). Reparation or retribution: An investigation into regulatory compliance in planning. Environment and Planning A, 37(7), 1249-1262. doi: $10.1068 / a 36288$

Mendes, L. (2014). Gentrificação e políticas de reabilitação urbana em Portugal: uma análise crítica à luz da tese rent gap de Neil Smith. Cadernos Metrópole, 16(32), 51-72. doi:10.1590/22369996.2014-3209

Munkøe, M. M. (2017). Regulating the European Sharing Economy: State of Play and Challenges. Intereconomics, 52(1), 38-44. doi:10.1007/ s10272-017-0641-3

República Portuguesa (2018). Plano nacional para o alojamento local. Lisboa: Portugal.

Segú, M. (2018). Do short-term rent platforms affect rents? Evidence from Airbnb in Barcelona.

Tanasescu, A., Wing-tak, E. C., \& Smart, A. (2010). Tops and bottoms: State tolerance of illegal housing in Hong Kong and Calgary. Habitat International, 34(4), 478-484. doi:10.1016/j. habitatint.2010.02.004

Turismo de Portugal, I. (2007). O Plano Estratégico Nacional do Turismo. Lisboa: Turismo de Portugal. 
Zaelke, D., Kaniaru, D., \& Kružiková, E. (2005). Compliance Theories. In D. Zaelke, D. Kaniaru, \& E. Kružiková (Eds.), Making law work: Environmental compliance \& sustainable development I (pp. 53-62). Cameron May Ltd., International Law Publishers.

Inês Calor (icalor@gmail.com). CEGOT - Departamento de Geografia da Universidade do Porto, Via Panorâmica, s/n, 4150-564 Porto, Portugal.

Mateus Magarotto (mateusmagarotto@gmail.com). LEGECE - Departamento de Oceanografia da Universidade Federal de Pernambuco, Avenida da Arquitetura, s/n, Cidade Universitária, 50750-550 Recife, Brasil e CEGOT Departamento de Geografia da Universidade do Porto, Via Panorâmica, s/n, 4150-564 Porto, Portugal. 